\title{
Investigation on Application of Rwanda Building Standards in Local Construction Industry
}

\author{
Mbereyaho Leopold $^{{ }^{*}}$, Abaho G. Gershome ${ }^{\text {, Mutabaruka Jean de Dieu }}{ }^{1}$, Ndayisenga Jean Claude ${ }^{1}$, \\ Niyomwungeri Evariste ${ }^{1}$, and Nsabimana Jacques ${ }^{1}$ \\ ${ }^{1}$ University of Rwanda, College of Science and Technology, P.O Box: 3900 Kigali-Rwanda. \\ "Principal author email: $\underline{\text { lmbereyaho2015@gmail.com }}$
}

\begin{abstract}
The Rwanda Building code is in place from 2015, while the development of Rwanda standards dates from 2006 when the reviewed Law establishing Rwanda Bureau of Standards (RBS) was published. The key role of standards is technically to ensure quality, safety, reliability of constructions as stated the relevant codes. With the construction industry growing very fast, the purpose of this study was to investigate on the application of Rwanda building standards, with regards to the existing code requirements and to identify the relevant gaps. The study was conducted based on initially set specific objectives, while the research methodology was mainly comprised of visits to different public and private agencies related to construction industry, observations on the sites and interview with different experts. The study established that Rwanda building standards were still accused of a low awareness and application as well as noticeable gaps. The level of awareness among all professionals was still at $71 \%$. In general about application, only 55\% of respondents confirmed the experience in application of Rwanda building standards, even if this level was higher for some categories. A good part of respondents composing around 57\% thought that Rwanda building standards documents were still incomplete. Based on the above findings, adequate strategies for improving the awareness, application process and document completion were proposed; with the introduction of Rwanda
\end{abstract}


building standards into academic curriculum, increase the number of awareness meetings and recognition of adequate research before design or review of any standard, among others.

Key words: Building code, Building Standards, awareness strategy, Law and Regulations, Monitoring process.

\section{Introduction}

The Rwanda Building code is in place from 2015, while the development of Rwanda standards dates from 2006 when the reviewed Law establishing Rwanda Bureau of Standards (RBS) was published. The purpose of this Code is to establish minimum requirements to safeguard public health, safety and general welfare by regulating and controlling the design, construction, quality of materials, etc. (Rwanda Building code, 2015, p.8). All activities pertaining to the development of Rwanda building standards date from 2006 when the reviewed Law establishing Rwanda Bureau of Standards (RBS) was published. Later in 2013, RBS was replaced by Rwanda Standards Board (RSB) after decoupling regulatory and non-regulatory functions and upgrading of Units into Divisions, to make the Institutions more effective and efficient. The last ten - fifteen years have been of a very rapid development of Rwanda construction industry, especially in the cities. Local construction industries are growing and they are indeed playing a very important role in the country development. Required better and sustainable buildings structures involves the application of building code and standards, which set guidance and standards of all structures. The lack of application of standards would result in the implementation of buildings which are not fit either for local safety conditions, or for aesthetic and functionality requirements. With reference to the Rwanda Building Code requirements, this study was 
undertaken to assess the level of public awareness of Rwanda building standards, their application in local construction industry, as well as their respective completeness status.

Some authors have conducted studies about the relevancy of national building code and results are available. A Standard is document, established by consensus and approved by a recognized body, that provides, for common and repeated use, rules, guidelines or characteristics for activities or their results, aimed at the achievement of the optimum degree of order in a given context (Hatto, 2010; Vaughan, 2013; Banerjee, 2015). Standards help codify international best practice and technical requirements to ensure buildings and other structures (known as civil engineering works) are safe and fit for purpose (ISO and construction, 2017). The standard can also lead to variety and cost reduction through optimization and best practice. Benefits of standards are very many and all stakeholders were beneficiaries (RSB website, Standards). Dahiru et al. (2012) conducted a study about an Evaluation of the Adequacy of the National Building Code (NBC) for achieving a Sustainable Built Environment in Nigeria, and respective results showed how the introduction of the NBC was a step forward in improving the quality of building products and hence, achieving sustainable built environment. Hatto (2001) described the roles of standards in modern society, and some of them were to provide a recognized means for assuring quality, safety, interoperability and reliability of products, processes and services as well as technical support for appropriate regulation; etc.

As this paper focus is specifically about Building standards and not Building Code, authors would like to present the significant and technical difference between both documents, just quoting one discussion on some of internet forums: "One way of looking at the differences between codes and standards is that a code tells you what you need to do, and a standard tells you how to do it. A code may say that a building must have a fire-alarm system. The standard 
will spell out what kind of system and how it must work....." (www.quora.com/What-is-thedifference-between-standards-and-codes). While the main objective of the study was the investigation on application of Rwanda Building Standards in local construction industry, the key specific objectives were among others, to identify the role of the country standards in development of building industry, to evaluate the public awareness with regards to Rwanda building standards, to assess the status with their application on construction sites, and to identify the gaps in that relevant document, as well as to propose strategies for improving the prevailing situation.

\section{Materials and Methods}

This study was survey based research and some of used data were collected from previous studies, while the great part of data was collected from experts' respondents. In order to achieve the above mentioned research objectives, the below presented methodology was used.

\subsection{Documents review}

The purpose of this review was to get the documented information about standards currently available in Rwanda and procedure followed in developing standards. Respective results are presented in the section 3.1

\subsection{Site visits, observation and interview supported by a questionnaire}

The questionnaire was designed and distributed to different experts (further indicated as respondents) in the engineering field from some construction companies visited, and government agencies whose activities are connected to the construction industry. Such agencies are Ministry of Infrastructure (MININFRA), Rwanda standard board (RSB), Rwanda housing Authority (RHA), Rwanda Transport Development Agency (RTDA), and One stop centers (OSC) of 
districts of Kigali city. The visited sites are ROKO construction company at I\&M BANK building construction site, REAL contractors company at the EDGE student's hostels for University of Rwanda Nyarugenge campus and GMK Architectural Rwanda limited, architectural designer and consultant company of the above hostels. Targeted people were experts in the engineering fields and researchers. The targeted respondents were all drawn from the city of Kigali as it was understood not only that it was where more important building were being implemented following the approved Master Plan, but also some of approached companies and people were the same working in secondary cities.

The purpose of the visits and interview was to get different views on application of Rwanda building codes and standards in local construction industry. In total 110 questionnaires were distributed to experts, selected using a stratified random sampling and 90 were collected back with respondents feedback. Respondents were composed of different categories including individual Practicing Engineers or Professionals (PE), contractors (CR), consultants (CT), technicians (TN), lecturers (LR) and students (ST). The table below gives the information about all respondents.

Table 1: Respondents and Position

\begin{tabular}{|l|c|l|c|}
\hline Position & Number & Percent & Cumulative percent \\
\hline Lecturer Engineer & 12 & 13.3 & 13.3 \\
\hline Practicing Engineer/Professional & 30 & 33.3 & 46.6 \\
\hline Technician & 10 & 11.1 & 57.7 \\
\hline Contractor \& Consultants & 18 & 20 & 77.7 \\
\hline Students Total & 20 & 22.3 & 100.0 \\
\hline \multicolumn{1}{c|}{ To } & 90 & 100 & \\
\hline
\end{tabular}


The graph in Fig.1 below presents the percentages of experts under above categories of respondents.

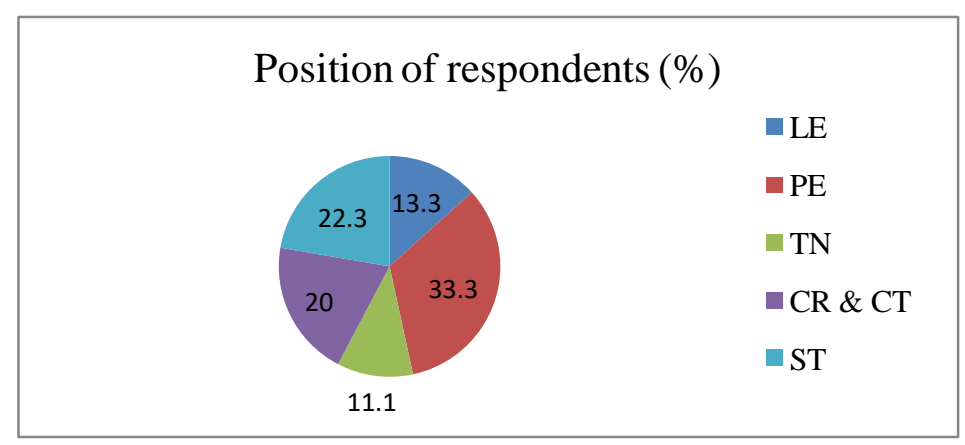

Figure 1: The position of the respondents

The collected data from respondents are shown in the subsection 3.2.

\subsection{Structure of the used questionnaire}

The questionnaire contained different and multiple choice questions related to the research topics and its objectives. The key needed information is presented below:

$\checkmark$ Awareness among professionals categories

$\checkmark$ Source of information about Rwanda building standards

$\checkmark$ Strategies used to increase public awareness on Rwanda building standards

$\checkmark$ Monitoring strategies for the application of Building standards

$\checkmark$ Individual experience in application of Rwanda building standards

$\checkmark$ Key challenges hindering the standards application

$\checkmark$ Current status of Rwanda building standards and gaps 


\section{Results}

\subsection{Results from documents review}

From the key and country strategic documents, the following information was summarized.

Standards currently available in Rwanda: Over 15 years of its existence, RSB has developed more than 2000 Standards in different categories/fields including engineering standards (building materials, electronics, electrical, IT, textile engineering etc.). Of the 2000 Standards, a big number are civil engineering standards, with specific focus on products widely used in Rwanda like cement, steel bars, wood poles, timber and timber products. RSB works closely with other government agencies and professional bodies. Their experts are involved in technical committees that develop Standards and in certification process as well as in inspections of construction sites. Construction materials require ascertainment or product certification to ensure they meet quality. Product certification provides quality assurance and safety to the contractors and society. Manufacturers benefit from having certified building materials as this builds their reputation, credibility and customer confidence of their brands, increase of market access and gives them a competitive edge (RSB, 2017).

Procedure followed in developing Standards: Ordinarily, Rwanda Standards Board develops standards on the request from the central government, SMEs or national policies that require Standards to be developed for a specific sector. Developing a Standard is not an easy process and it is costly, requires a lot of technical input and takes time. Standards are developed in the technical committees composed by experts drawn from relevant fields. On average, product Standards development takes between 6-9 months, but it can extend to a year depending on the technicality and uniqueness of the product (RSB, 2017) 


\subsection{Interview using a questionnaire}

Results from the interview, as discussed in the subsection 2.2 are summarized in the table 1presented below.

Table 1: Summary of the key collected data from interview

\begin{tabular}{|c|c|c|c|c|c|c|c|}
\hline \multirow[t]{2}{*}{$\mathbf{S} / \mathbf{N}$} & \multirow[t]{2}{*}{ Information needed } & \multicolumn{6}{|c|}{ Respondents and number $($ Total number $=90)$} \\
\hline & & $P E(30)$ & $\begin{array}{l}C R \& C T \\
(18)\end{array}$ & $L R(12)$ & $T N(10)$ & $S T(20)$ & $\begin{array}{l}\text { Total } \\
90 \\
=100 \%\end{array}$ \\
\hline \multirow[b]{2}{*}{1} & $\begin{array}{l}\text { Awareness among } \\
\text { professionals categories } \\
\text { (in figure) }\end{array}$ & 21 & 13 & 12 & 7 & 11 & 64 \\
\hline & In $\%$ & 70 & 72 & 100 & 70 & 55 & 71.1 \\
\hline \multirow{3}{*}{2} & $\begin{array}{l}\text { Source of information } \\
\text { for those who are aware } \\
\text { (64/90 respondents) }\end{array}$ & $\begin{array}{c}\text { Personal } \\
\text { research } \\
\text { (not media) }\end{array}$ & $\begin{array}{l}\text { Seminars } \\
\text { attended }\end{array}$ & $\begin{array}{l}\text { Class } \\
\text { attended }\end{array}$ & Client & Media & others \\
\hline & In figure & 23 & 8 & 6 & 6 & 16 & 5 \\
\hline & In $\%$ & 36 & 13 & 9 & 9 & 25 & 8 \\
\hline \multirow{3}{*}{3} & $\begin{array}{l}\text { Suggested Strategies to } \\
\text { be used to increase } \\
\text { public awareness (by } 90 \\
\text { respondents) }\end{array}$ & $\begin{array}{l}\text { Seminars } \\
\text { and } \\
\text { workshops }\end{array}$ & $\begin{array}{c}\text { Building } \\
\text { inspection } \\
\text { campaign }\end{array}$ & $\begin{array}{c}\text { Motivatio } \\
n \text { awards }\end{array}$ & $\begin{array}{l}\text { Punishme } \\
n t \\
\text { measures }\end{array}$ & $\begin{array}{l}\text { Introductio } \\
n \text { into } \\
\text { curriculum }\end{array}$ & Others \\
\hline & In figure & 29 & 21 & 3 & 10 & 27 & 0 \\
\hline & In $\%$ & 32 & 23 & 4 & 11 & 30 & 0 \\
\hline \multirow{4}{*}{4} & $\begin{array}{l}\text { Suggested Monitoring } \\
\text { strategies (by } 90 \\
\text { respondents) }\end{array}$ & Inspection & Evaluation & Audit & Research & Others & Total \\
\hline & In figure (out of 90) & 34 & 19 & 24 & 6 & 7 & 90 \\
\hline & In $\%$ & 38 & 21 & 27 & 6 & 8 & 100 \\
\hline & $\begin{array}{l}\text { Current status of } \\
\text { Rwanda building } \\
\text { standards }\end{array}$ & Complete & Incomplete & $\begin{array}{c}\text { Not } \\
\text { aware }\end{array}$ & $N / A$ & $N / A$ & Total \\
\hline
\end{tabular}




\begin{tabular}{|c|c|c|c|c|c|c|c|}
\hline 5 & In figure (out of 90) & 0 & 51 & 39 & - & - & 90 \\
\hline 5 & In $\%$ & 0 & 57 & 43 & - & - & 100 \\
\hline \multirow{3}{*}{ ( } & $\begin{array}{l}\text { Experience in } \\
\text { application of Rwanda } \\
\text { building standards. }\end{array}$ & $P E(21)$ & $\begin{array}{l}C R \& C T \\
\text { (13) }\end{array}$ & $L R(12)$ & $T N(7)$ & $S T(11)$ & $\begin{array}{l}\text { Totall } \\
64\end{array}$ \\
\hline & In figure (out of 90) & 14 & 9 & 8 & 2 & 2 & 35 \\
\hline & In $\%$ & 67 & 69 & 67 & 29 & 18 & $55 \%$ \\
\hline \multirow{3}{*}{7} & $\begin{array}{l}\text { Key challenges } \\
\text { hindering the standards } \\
\text { application }\end{array}$ & $\begin{array}{c}\text { Limited } \\
\text { access to } \\
\text { documents }\end{array}$ & $\begin{array}{c}\text { Lack of } \\
\text { urban } \\
\text { investment }\end{array}$ & $\begin{array}{c}\text { Lack of } \\
\text { knowledg } \\
\text { e in } \\
\text { practice }\end{array}$ & $\begin{array}{c}\text { Lack of } \\
\text { awareness }\end{array}$ & Mindset & Others \\
\hline & In figure (out of 90) & 58 & 44 & 60 & 62 & 52 & 27 \\
\hline & In $\%$ & 64 & 49 & 67 & 69 & 58 & 30 \\
\hline
\end{tabular}

Data from the above table were used to plot the charts in Figs. 2-7.

Awareness about Rwanda building standards among professionals' categories: The respective results from the table are presented under the graph in Fig.2.

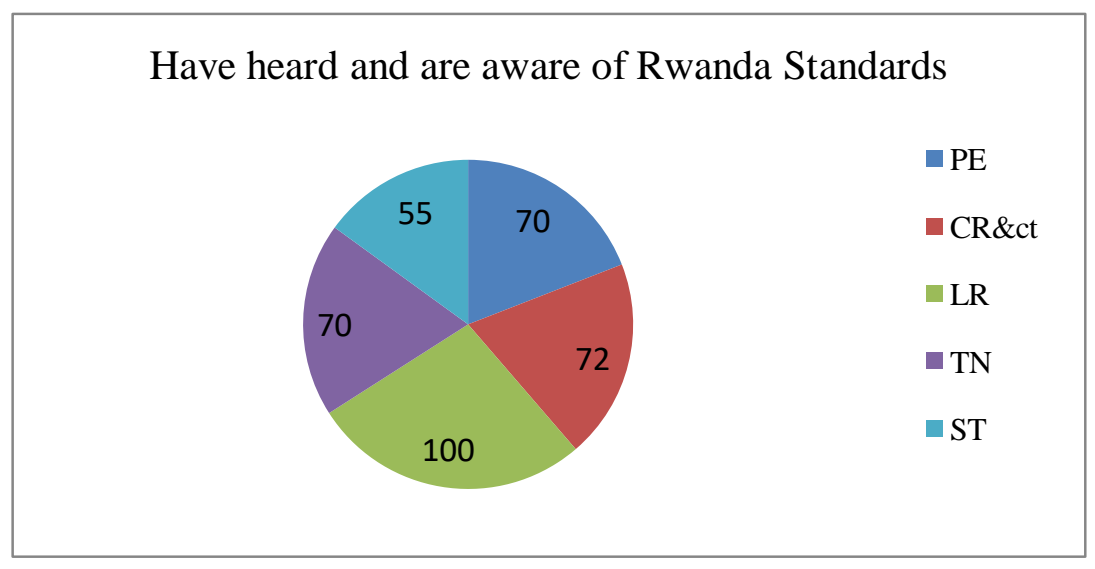

Figure 2: Awareness among professionals about Rwanda building standards 
According to the results in the table, only around $71 \%$ of respondents confirmed that they had heard and were aware of the existence of Rwanda building standards. The Fig.2 shows the awarenes level among all experts cathegories, with a full awareness of $100 \%$ for lecturers Engineers, and however with a lower awareness level among students, who should be the most important targeted group as the country future with only $55 \%$.

Source of information about Rwanda building standards: The respective results are used to plot the graph in Fig. 3 below.

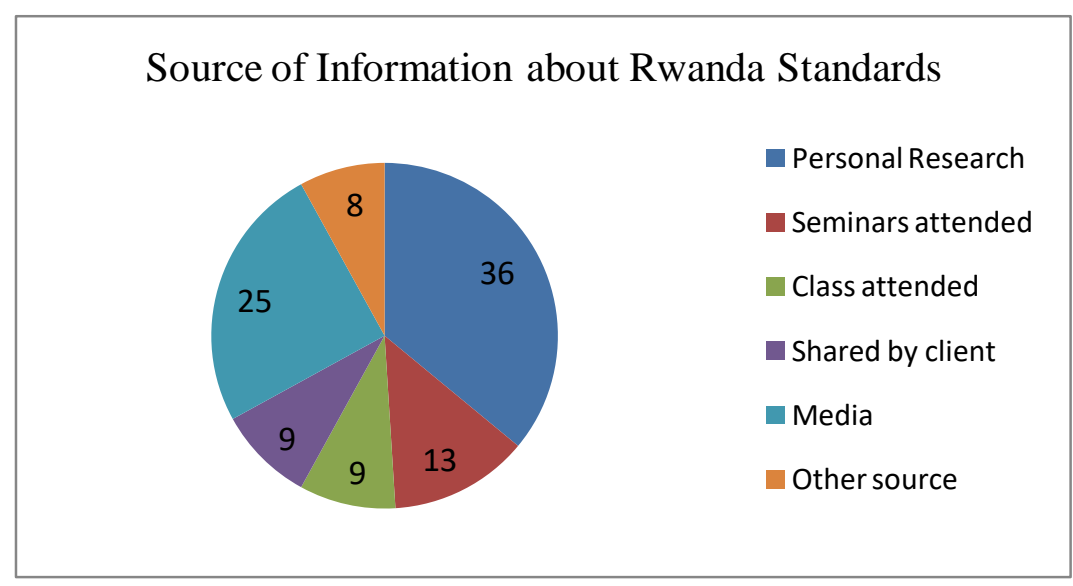

Figure 3: Source of information about Rwanda building standards

It can be noted that the most important source of information was individual research as confirmed $36 \%$, while the attendance of classes was among the unknown source as was confirmed only by $9 \%$.

Strategies to be used to increase the application of Rwanda building standards: The responses from responded are presented in the graph under Fig. 4 


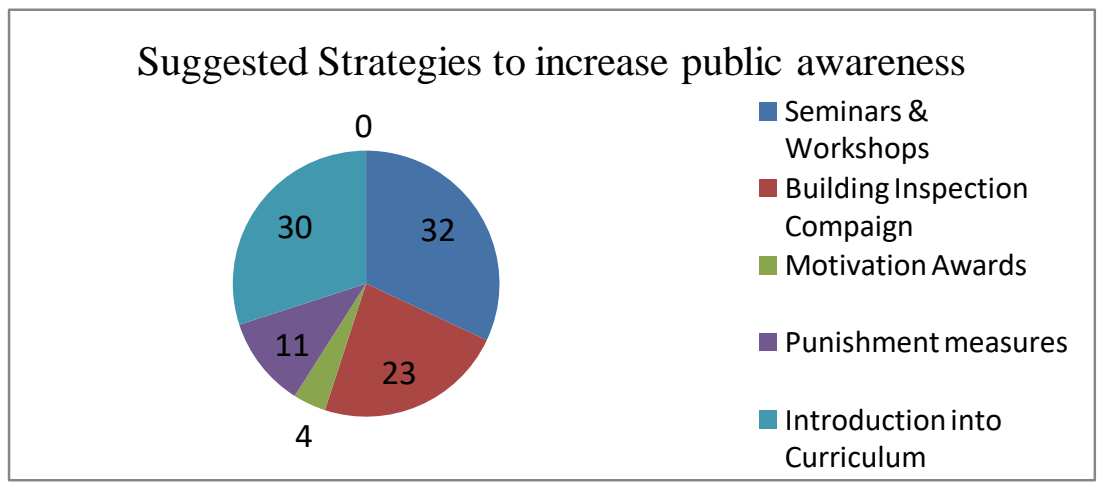

Figure 4: Measures for application increase on Rwanda building standards

The results showed that $32 \%$ of respondents supported the use of seminars and workshop, $30 \%$ for the introduction of Building standards into academic curriculum, and $23 \%$ the building inspection campaigns. The motivation looks not to be a well appreciated measure for increasing the application of Rwanda building standards.

Monitoring strategies for the application of Rwanda building standards: The respective feedback from respondents is presented in the diagram under Fig. 5 below.

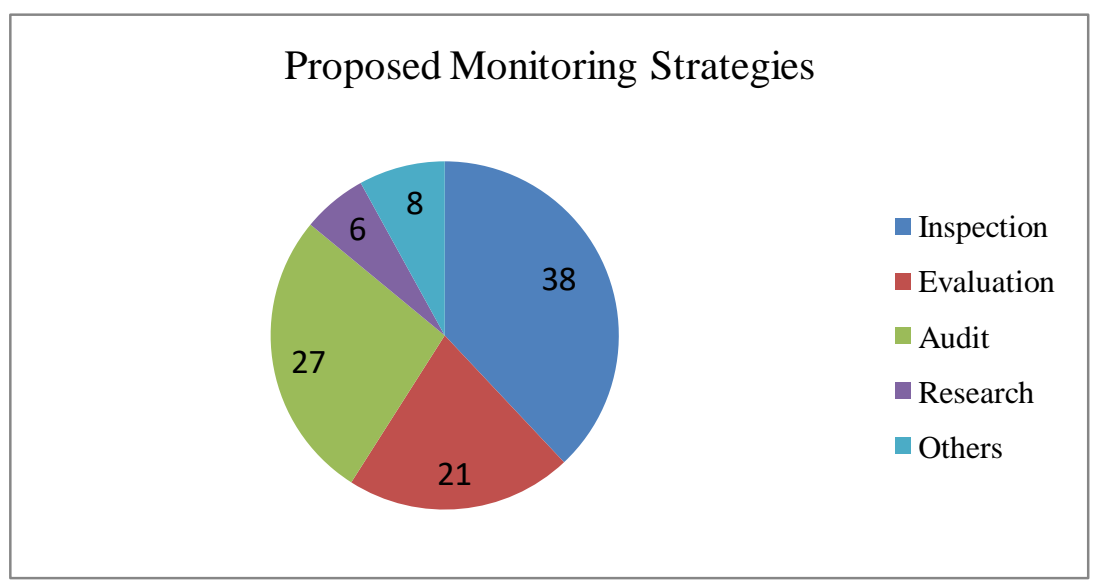

Figure 5: Government monitoring strategies 
The above diagram shows that the better monitoring approach should be the regular inspection with support from $37 \%$ of respondents. The regular survey based research did not convince a good part of respondents as only $6 \%$ of them found it as a good strategy.

Current completion status of Rwanda building standards and gaps: Respondents views are summarized in the Fig. 6 below.

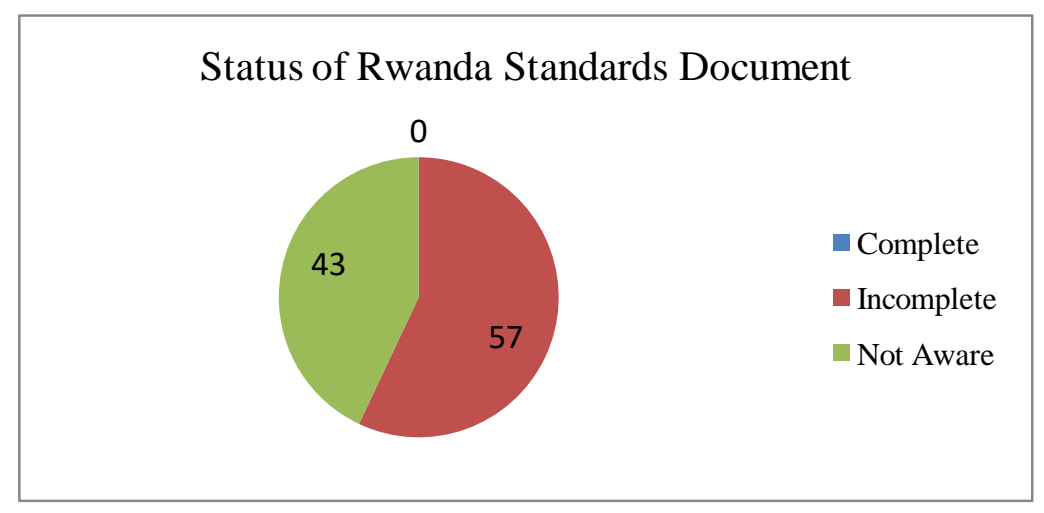

Figure 6: Status of Rwanda building standards

From the respondents' views, it could be realized that the majority of them at $57 \%$ consider that Rwanda building standards were still incomplete, while $43 \%$ were not aware of the status. As this questions requested to identify gaps for those who selected "incomplete" as their answer, suggested gaps were standards on disaster mitigation and management (storm water management, flood management), earthquake design, standards on design for physical disability facilities, while standards about fire protection and Cities Master plans development needed updates.

Individual experience in application of Rwanda standards: Information about how different experts were applying Rwanda Standards is presented in Fig.7 below. 


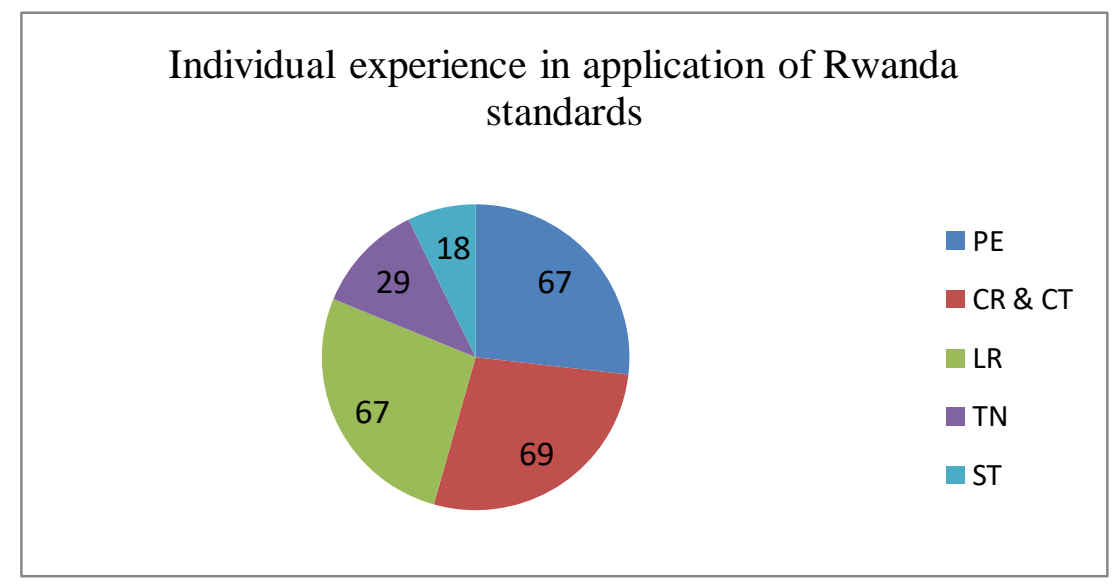

Figure 7: Application of Rwanda standards

According to the results in the table 2, only around $55 \%$ of respondents confirmed that they had personally applied at least once the Rwanda building standards. The graph in Fig.7 above suggests that Practicing Engineers/Professionals, consultants and contractors, and lecturers were only satisfactorily applying Rwanda Building Standards at 67\%, 69\% and 67\% respectively. Students who were the future of the country were yet to fill the application in their key business (studies) where only $18 \%$ were applying them.

\section{Problems hindering the application of Rwanda building standards in local construction industry: Results from the table 2 were used to present the levels of suggested problems in Fig.8.}




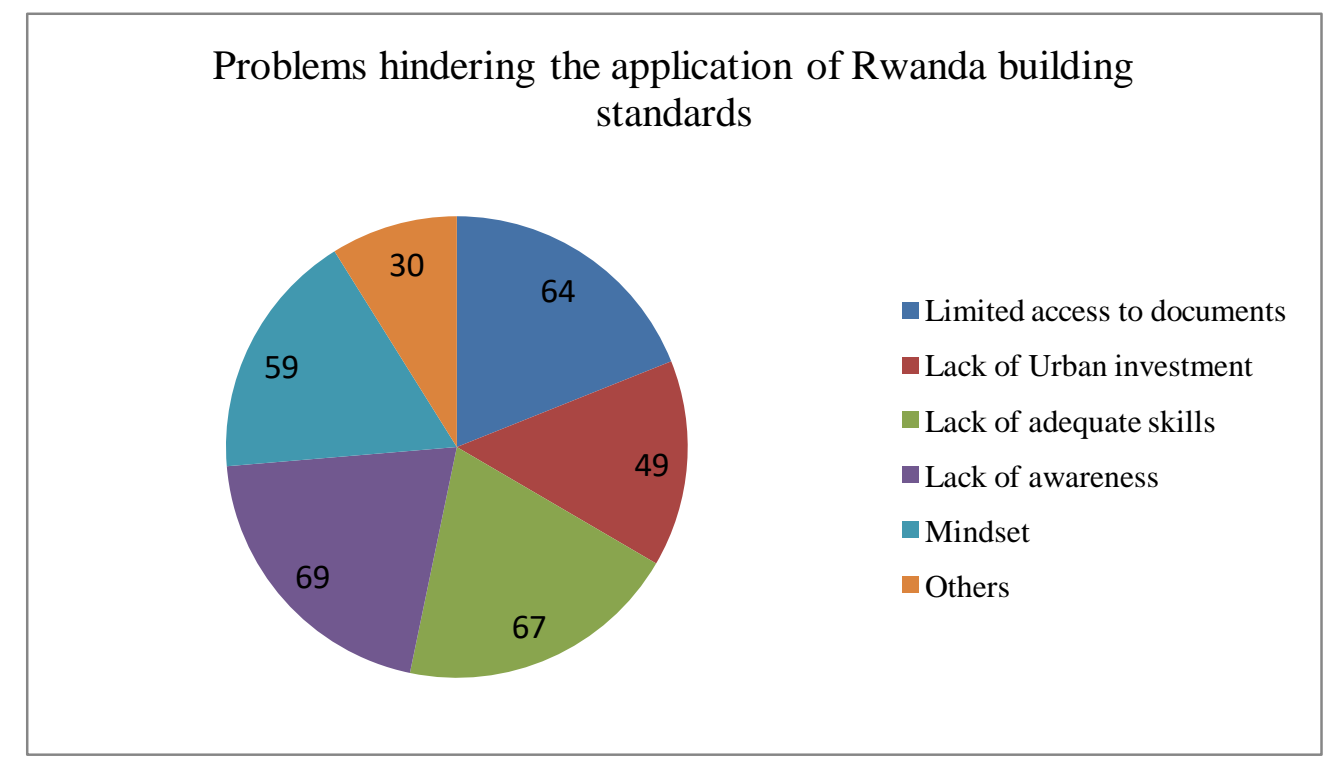

Figure 8: Challenges hindering the application process

From the results presented in Fig. 8 above, it can be seen that the majority of respondents (around $69 \%$ ) considered the lack of awareness as the main problem. Others suggested challenges were lack of adequate skills in adaptation of new standards (67\%), limited access to the documents (64\%), and Mindset (80\%). Few respondents see the lack of urban investment as a relevant problem.

\section{Discussion}

There was an agreement between few available resources and findings from the study regarding the status of Rwanda building standards. The building standards document and the related CODE are important for the health construction industry (Rwanda Building code, 2015; Peter Hatto, 2012). Key results are discussed below.

(1) The level of awareness and application of Rwanda Building standards in construction industry and in Higher Learning Institutions was still low. The level of awareness among all professionals was still at $71 \%$, and had a room for improvement. Only lecturers were aware 
at $100 \%$, and even the awareness among engineering students, considered as the country future in the field had attained only 55\%. The most important source of information was individual research as confirmed the good part of respondents (36\%), and this was not very suitable for professionals who were regularly busy on the construction sites. About application, only 55\% of respondents confirmed the experience in application of Rwanda building standards, while in academia only $18 \%$ of students happened to apply them at least once. Among key challenges hindering the Rwanda building standards application, the limited awareness company, limited knowledge and skills in practice, limited access to documents, and mindset were cited among others.

(2) For experts in the field, there was no prevailing among all proposed monitoring strategies to be used for promotion of standards application. However, a slight importance was given to the inspection supported by only $38 \%$ of respondents. This was in line with what RHA and RSB were doing but they should strengthen that audit and evaluation, also suggested by respondents.

(3) Rwanda building standards were still incomplete, as it was confirmed by the good part of respondents (57\%), while the remaining part of respondents composing $43 \%$ was not aware of the existence of those standards. The underlined main gaps were standards on disaster mitigation and management, such as storm water management and flood management, earthquake design, wind design, design standards for physical disability facilities while standards about fire protection and Cities Master plan development needed updates. This respondent observation serves as a call for consideration of some other areas such as personal hygiene, comfort and well-being of people, etc (Bergeron D., 2003). 


\section{Conclusion and Recommendations}

The study was intended to assess the applicability level of Rwanda building standards in local construction industry, the completeness of the standards, and to propose relevant measures for improvement. The study results showed that the application of Rwanda Building Standards and even its awareness were still low. The already adopted measures used to increase the awareness and therefore promote the application of Rwanda building standards, such as building inspection, use of all relevant sources of information, involvement of representatives from all relevant agencies and institutions in designing building standards, etc. needed to be more aggressive. The study showed that a more effort should be made in conducting seminars and workshops, and in collaboration with higher learning institutions for the introduction of building standards into academic curriculum. Furthermore, there was a need in strategy for making more accessible and affordable the available standards documents to all relevant agencies with consideration of their financial capacity. Finally, a good part of respondents $(57 \%)$, think that Rwanda building standards were still incomplete, and the office in charge should make sure that all gaps in standards were defined by experts in the fields, while any standards design or review should be preceded by adequate research, necessarily with the involvement of higher learning Institution. As many previous studies showed clearly and in details elaborated, the Building standards were the only official and common country tool aiming at improving the quality and safety of building products and hence, achieving sustainable built environment. Therefore the agency in charge (currently RSB) should make sure the Rwanda standards well designed, complete and accessible, so that each company or individuals working in construction industry comply with these standards, or be subjected to consequences underlined in the relevant Code or Law. 


\section{Acknowledgement}

Authors would like to thank all individuals, agencies and companies who kindly participated in the interview and offered their very priceless views, as were stated in the manuscript. A special appreciation goes to the leadership of University of Rwanda College of Science and Technology for moral and academic support during research process.

\section{References}

Banerjee R. (2015). Importance of Building Code. International Journal of Engineering Research and Applications, 94-95.

Bergeron D. (2003). Role of Acceptable Solutions in Evaluating Innovative Designs. Proceedings of the CIB-CTBUH International Conference on Tall Buildings, Malaysia.

Dahiru D., Abdulazeez A.D., Muawiyya A. (2012). An Evaluation of the Adequacy of the National Building Code for Achieving a Sustainable Built Environment in Nigeria. Research Journal of Environmental and Earth Sciences 4(10): 857-865.

International Organization for Standardization (ISO), 2017; Geneva. Switzerland

Hatto P. (2001). Standards and Standardization, A practical guide for researchers. European Commission Directorate-General For Research \& Innovation

Hatto P. (2010). Standards and Standardization Handbook. European Commission

Republic of Rwanda, Rwanda Building code, $1^{\text {st }}$ edition, 2015

Rwanda Standards Board (RSB). Rwanda Standards Journal, May 2017

Vaughan E. ( 2013). The Value and Impact of Building Codes. Newsletters, 1-12. 